\title{
A REPRESENTAÇÃO IMAGINAL, OS DADOS SENSÍVEIS E OS JOGOS DA MEMÓRIA: OS DESAFIOS DO CAMPO DE UMA ETNOGRAFIA SONORA
}

\author{
Ana Luiza Carvalho da Rocha \\ Viviane Vedana
}

\begin{abstract}
A poética urbana se justifica tanto por uma dimensão ética como por uma dimensão estética.
Estética, ela nos parece mais frutuosa, para um bom regime de imaginação, de insistir sobre o vai e vem sobre os acordos da cidade e dos homens.
\end{abstract}

(Pierre Sansot, 1986:419).

Este trabalho trata de resultados de pesquisa antropológica desenvolvida no interior do Banco de Imagens e Efeitos Visuais sobre as produções de coleções etnográficas sonoras como parte da pesquisa com memória coletiva, cotidiano, formas de sociabilidades e itinerários urbanos nas grandes metrópoles contemporâneas, em particular, na cidade de Porto Alegre ${ }^{1}$.

Ao longo dos últimos 3 anos o grupo de pesquisa com etnografia sonora no interior do BIEV vem se dedicando ao estudo das sonoridades dos territórios urbanos, das intensidades das atmosferas sonoras que acompanham as comunicações verbais entre seus habitantes, das ambiências sonoras que configuram as formas de vida social cotidiana nas modernas sociedades complexas como parte da pesquisa em torno do estatuto da representação etnográfica para a produção do pensamento antropológico.

\section{O caráter objetal da antropologia sonora em sua feição temporal}

Nosso conhecimento da realidade, de tudo aquilo que esta fora de nós, se processa pela via da representação, na linguagem, que possui um caráter material, expresso através de alguns aspectos como um conjunto de sons articulados (a fala), redes de marcas escritas ou cadeias de gestos (Kristeva, 2003). É através da linguagem que articulamos um conhecimento do mundo e dos outros, atribuindo sentido às coisas, aos fenômenos e às experiências vividas. Uma das formas de se processar este conhecimento da realidade são as trocas verbais entre os

\footnotetext{
${ }^{1}$ Em especial, gostaríamos de situar a etnografia realizada por Priscila Farfan (bolsa de Iniciação Científica Fapergs) no Centro da cidade de Porto Alegre, sobre os pregões de vendedores ambulantes de cd's e dvd's, bem como a pesquisa etnográfica de Luciana Mello (mestranda PPGAS/UFRGS) no Bairro Navegantes, também em Porto Alegre sobre as narrativas de antigos morados e as melodias da memória. Duas pesquisas que inspiraram este texto, além da pesquisa sobre formas de sociabilidade e a circulação da palavra nas cidades contemporâneas de Viviane Vedana (Doutoranda, PPGAS/UFRGS).
} 
sujeitos, onde se comunicam mensagens e pensamentos, através das quais se estabelecem diálogos. Para o caso da antropologia, esta comunicação, estes diálogos, são aspectos fundamentais das formas da vida social e sua observação, a compreensão de tudo que envolve seqüências de atos de fala, como as posturas e gestos, os sotaques e entonações, o conteúdo dos enunciados, enfim, tudo o que conforma uma "arte de dizer" (De Certeau, 1994) faz parte de conhecer a cultura do outro e suas formas de expressão. Roberto Cardoso de Oliveira em "O Trabalho do Antropólogo" analisa "o caráter constitutivo do olhar, do ouvir e do escrever, na elaboração do conhecimento próprio das disciplinas sociais" (Oliveira, 2000:18), procedimentos e gestos de pesquisa que estão "disciplinados" pelos paradigmas e teorias da Antropologia. Ao preocupar-se com o ouvir, Roberto Cardoso de Oliveira aponta para o caráter dialógico da relação entre pesquisador e informante no momento em que este último é transformado em interlocutor, ou seja, enfatiza a "habilidade de ouvir o nativo e por ele ser igualmente ouvido". Para as pesquisas em etnografia sonora no Biev, esta escuta ganha uma dimensão ainda mais complexa - já que para Cardoso de Oliveira estava relacionada mais especificamente com os momentos de entrevista - revelando-se como uma escuta das formas da vida social, através das expressões culturais engendradas pelos habitantes das cidades.

$\mathrm{Na}$ linha das reivindicações de Margareth Mead (1975) as quais se direcionavam as diversas possibilidades de registro dos dados de campo (visuais e sonoras, para além das anotações de cadernos de campo), sendo a antropologia uma disciplina de palavras - escritas pelo antropólogo, mas também enunciadas pelos nativos - propomos a investigação de métodos e procedimentos onde as imagens sonoras da vida social possam tomar corpo e dessa forma serem também expressivas da cultura de uma comunidade. Trata-se no caso, de intervenção metodológica e científica inspirada na abordagem de uma antropologia das formas sensíveis, de observações dos sons do minúsculo, do banal e do ordinário das nossas vidas nas grandes metrópoles. A rigidez de um quadro interpretativo é contraposto a uma microantropologia da observação do pequeno e do ordinário nas sonoridades através das quais a pluralidade do social se apresenta.

A exacerbação dos sentidos (Simmel, 2004), a exaltação do sensível (Sansot, 1986) o sensualismo coletivo (Maffesoli, 1990), o realismo sensorial (Durand, 1984) são expressões apontadas por inúmeros autores para tratar os fenômenos que configuram a experiência da vida humana nas grandes metrópoles moderno-contemporâneas. Elas reúnem o mundo das imagens, das coisas, dos objetos e das pessoas aos dados sensíveis das formas dos arranjos que a vida social assume no interior das metrópoles: conjunto de formas, de cores, de sons que anunciam a presença forte do imaginário como forma de se penetrar na espessa vida 
coletiva formada das expressões verbais e corporais tanto quanto das ambiências e atmosferas sonoras através das quais a vida coletiva cria e recria as modernas sociedades complexas, urbano-industriais como expressão estética.

A pesquisa com etnografia sonora, no interior do BIEV, portanto, aponta para a escuta das práticas sensíveis das formas de sociabilidades ordinárias que se apresentam no dia-a-dia dos grupos urbanos. Da figura das grandes metrópoles, muitas vezes tomadas como representações caóticas de modernização e progresso, onde as sonoridades são diretamente relacionadas com poluição sonora, procuramos observar o que não é sempre visível e está fora dos limites materiais dos bairros, das calçadas, dos percursos, das casas e edifícios, das esquinas, dos bares, das ruas, dos parques e das praças. As grandes cidades são assim reveladas pelo etnógrafo como parte das impressões fugidias e das figuras ambíguas de seus modos de vida e de suas práticas culturais cotidianas, reunindo forma e matéria desde suas expressões mais familiares.

$\mathrm{Na}$ etnografia sonora a descrição dos lugares dos excessos e dos prazeres que configuram a vida social numa forma, são aqui aspectos fundamentais desta microantropologia. A escuta das sonoridades dos objetos e artefatos trocados e tocados: pratos, garrafas e copos, no interior dos bares, chaleiras, talheres e panelas nas moradias, regadas às distintas melodias das vozes de conversas, risadas e piadas; as buzinas dos carros, de bicicletas ou ruídos de freios e travadas de pneus, no asfalto ou nos paralelepípedos, apitos de fábricas; os sons dos gestos de dedilhar um violão, de sussurros segredados ao pé do ouvido por namorados, da tragada de um cigarro, do borbulhar da bebida num copo, tudo se compõe de dados sensíveis da vida coletiva que conformam uma ambiência urbana em sua manifestação mais banal.

Cada um dos sons emitidos, fabricados, produzidos pelo encontro entre corpos e almas tornam-se, no interior de uma etnografia sonora, objeto de descrição para o antropólogo interessado nas formas como a existência social e coletiva se processa no interior das grandes metrópoles contemporâneas. Todos eles remetem à simbólica das posturas, das técnicas, dos rituais, etc., enfim, das formas do corpo coletivo se dar a ver, atribuindo, a partir de suas formas simbólicas, um sentido, um determinado cheiro e um certo sabor a determinados territórios e lugares da vida social nas grandes cidades. 


\section{A etnografia sonora, a memória coletiva e a duração}

Para se enfrentar esta pesquisa antropológica com sons uma das primeiras questões que se coloca seria a diferença complementar que une a uma etnografia do sonoro a uma etnografia sonora uma vez que a pesquisa antropológica dos sons, para além de sua manifestação como parte de um conjunto organizado de sentido para uma determinada ordem social, como a música, transcorre por e através dos sons em suas modalidades distintas de configurar conjuntos de símbolos de uma cultura. A acústica como ramo do conhecimento da Física que estuda o som, seus meios de propagação, transmissão e recepção, tanto quanto a música, aparecem, neste contexto interpretativo, como parte integrante de um conjunto de símbolos organizados culturalmente, e embora de natureza distinta, dialogam entre si no caso das modernas sociedades ocidentais ${ }^{2}$.

No âmbito da prática da pesquisa antropológica nas modernas sociedades complexas, a etnografia sonora faz, portanto, parte de uma etnografia das formas sensíveis da vida social, onde o som representa uma importante fonte de informações sensíveis das formas e arranjos da vida coletiva no teatro da vida urbana das grandes cidades contemporâneas.

A Antropologia Sonora estaria aqui destinada ao estudo do sentido dos sons de que toda a vida coletiva é depositaria em sua manifestação banal, na contramão do destino trágico de uma existência humana arrítmica e atonal, que representaria a morte do próprio corpo coletivo. Os sons em sua face menos nobre, na vida ordinária dos grupos humanos, conformam o sentido de suas vidas num corpo coletivo. Logo, uma antropologia sonora está associada aos estudos e pesquisas acerca do imaginário, jogando a favor da imaginação criadora humana, aquela que retira o mundo cósmico e social de toda indiferença, atribuindo sentido a existência humana e interrompendo sua indistinção do mundo das coisas. Uma antropologia sonora retoma a cidade no que ela configura como partilha do sensível, ou seja, pela forma como a vida urbana contemporânea se apresenta fora das hierarquias da representação de um corpo comunitário, geralmente dividido entre pobres e ricos, brancos e negros, centro e periferia, povo e elite, zona sul e zona norte, bairros residenciais e bairros comerciais, etc.

A antropologia sonora abandona o mutismo desta hierarquia da representação das grandes metrópoles contemporâneas como território do anonimato, do exílio, etc. e persegue,

\footnotetext{
${ }^{2}$ A observação de que a altura do som produzido por uma corda vibratória varia com o seu comprimento é atribuída a Pitágoras (séc. VI a.C.) descoberta que o levou à da escala musical, em que ainda se baseia a música ocidental. Na música, a acústica é importantíssima, pois sem o estudo desta não é possível o desenvolvimento e o processo de criação artística. Sem o estudo do som, suas combinações, harmonia, interações entre as notas musicais não existe.
} 
bem o contrário, as formas mais sensoriais de seus bairros e ruas, casas e bares, a dos cheiros, a dos odores, a dos ruídos, a dos barulhos, etc. que exalam dos modos coletivos do viver nas cidades moderno-contemporâneas.

Neste contexto, a prática da etnografia se configura no ato de devanear a forma como a experiência humana adere aos diferentes territórios da vida coletiva no contexto das grandes metrópoles. Os sons se destacam aqui como uma forma singular que as cidades modernocontemporâneas adotam como fenômeno da ordem do sensível, num processo que alia a expressão poética do antropólogo-etnógrafo ao seu olhar concreto sobre os seres e as coisas que estão ali em co-presença.

A prática da etnografia sonora se constitui, assim, como parte da pesquisa antropológica no mundo urbano contemporâneo pela via de sua expressão sensível e sensorial, por tudo aquilo que afeta nosso sentido na prática de uma antropologia da cidade na cidade. As formas da vida urbana, as cores e cheiros que a revelam, assim como os sons que a fabricam e que são por ela fabricados e que afetam o destino de seus habitantes em sua vida cotidiana são parte integrante da pesquisa em Antropologia sonora.

Trata-se mais de um desafio do que um protocolo de ações: conciliar a norma metodológica da prática da ciência antropológica na cidade para desde aí construir um conhecimento da cidade e a restituição da poética das formas sonoras que os lugares da vida urbana sugerem aos seus habitantes.

\section{Uma proposta de heterogeneidade metodológica e a etnografia sonora da cidade} na adesão às suas formas sensíveis

Mas o que seria, afinal, o que denominamos aqui de uma etnografia sonora? Como etno-grafar o dado sensível que o fenômeno sonoro desenha como parte das formas de vida urbana contemporânea? Como estabelecer algum parâmetro interpretativo para a investigação das formas sonoras que adotam a vida humana nas grandes metrópoles? Como pensar os sons e as imagens sonoras que emitem as formas da vida social nos grandes centros urbanoindustriais?

Estas questões são colocadas aqui a partir de uma trajetória de pesquisa na qual temos nos perguntado sobre o som, não de uma forma geral, mas efetivamente relacionado ao viver urbano e as formas sensíveis através das quais os laços sociais figuram o dia-a-dia na cidade. É necessário, neste caso, ensaiar algumas reflexões, não definitivas, mas investigativas sobre estas perguntas para as quais não temos respostas, mas com a intenção de precisar um pouco mais este percurso de investigação no interior do Banco de Imagens e Efeitos Visuais. 
A proposta de procedimentos e técnicas de pesquisa em etnografia sonora situa-se no interior de uma proposta bachelardiana de um pensamento que pensa através do devaneio daquilo que é pensado, numa busca de conciliar um pensamento interpretativo da vida social desde as formas sonoras sensíveis através das quais elas se apresentam à escuta antropológica como parte de seus procedimentos de observação da vida cotidiana dos habitantes de um grande centro urbano-industrial.

A pesquisa do som como parte dos dados sensíveis da vida coletiva nas metrópoles impõe-nos uma breve reflexão sobre o fenômeno sonoro como parte integrante do estudo da memória coletiva, que serve de referência e de princípio descritivo da pesquisa a respeito das feições do tempo na contemporaneidade. Ela amplia e amplifica a pesquisa das formas de vida coletiva nos grandes centros urbanos. Os sons e suas sonoridades alusivas a paisagens urbanas presentes ou passadas permitem descrever o sensível como da ordem da duração dos fenômenos temporais. Mais do que a forma do ethos que uma determinada forma de vida urbana funda, a etnografia sonora aponta para uma pesquisa do seu eidos, da percepção que se tem dos seres e das coisas que se escondem no interior de tais formas.

O pensar o fenômeno sonoro no âmbito das formas sensíveis e expressivas através das quais as práticas culturais humanas se dão a ver e a ouvir para o olhar e a escuta antropológicas não é um percurso original. Franz Boas (2004) já comentava, em seus estudos a respeito dos sons alternantes, ou seja, das formas de percepção das sonoridades da língua falada que realizou durante seu trabalho de campo com os grupos Haida, Kwakiutl e esquimós, inspirado também em pesquisas com crianças nas escolas da Inglaterra e de filólogos e suas coleções de textos e palavras, sobre o caráter cultural da percepção dos sons. Trazendo a tona diferenças milimétricas entre escutas, comparando audição e visão, cores e sons, Franz Boas apontava que a idéia de sons alternantes poderia ser aplicada a qualquer língua, ou seja, não indicava nenhum "primitivismo da língua” (Boas, 2004), mas diferenças de percepção sonora que se constituem nas práticas e atos de fala, definidos culturalmente a partir do exercício da língua ${ }^{3}$. Em termos de uma trajetória de preocupações da antropologia com as sonoridades do mundo, nos estudos de Boas podemos perceber o caráter de fenômeno cultural atribuído ao som, pela via da linguagem, já que falar, enunciar palavras, entoar cantos, fazer perceber a voz, depende de uma aprendizagem oral (pela escuta) e que se conforma a partir da articulação de diversos órgãos do corpo humano (como pulmões, laringe,

\footnotetext{
${ }^{3}$ Segundo Kristeva (2003) "é necessário distinguir cuidadosamente este som, portador de sentido, dos diferentes gritos que servem de meio de comunicação entre os animais. O som lingüístico pertence a uma categoria completamente diferente visto que instaura este sistema de diferenciação, de significação e de comunicação que é a língua no sentido que lhe demos atrás, e que pertence apenas a sociedade humana".
} 
palato, nariz, língua, dentes, lábios, etc), uma articulação cultural, já que cada língua vai exigir combinações diferenciadas para produzir determinados sons.

$\mathrm{Na}$ tradição boasiana da pesquisa em Antropologia, a riqueza simbólica da voz humana, da fala e da pronúncia das palavras, dos sons, apontavam para sua importância para o antropólogo na sua apreensão cultural do ambiente vivido por um determinado grupo humano. Margaret Mead (1975), na trilha desta perspectiva, é que irá discutir aqui os limites que cercam o fato da Antropologia ser uma "disciplina de palavras", ressaltando o atributo de visualidade de toda a cultura humana; a dimensão especifica das sonoridades banais, fora da espetacularização do sagrado e do sensível amplificado nos rituais e nas cerimônias, entretanto, lhe escapam.

No pensamento de Lévi-Strauss, o fenômeno sonoro, como forma sensível da vida social que se apresenta aos antropólogos, aparece particularmente nos seus estudos sobre a música, numa perspectiva estruturalista, em diferentes obras ${ }^{4}$. Especificamente em " $O$ cru e o cozido. Mitológicas 1. (2004)", Levi-Strauss constitui uma importante análise de mitos para refletir sobre o tema da passagem da natureza para a cultura e, nesta obra, o fenômeno sonoro na sua feição musical torna-se metáfora para pensar as estruturas dos mitos. Esta passagem da natureza para a cultura estaria significada, ou representada, em termos das dualidades como cru e cozido, ruído e som, dia e noite, vida e morte, no interior destes mitos. Mais uma vez reafirma-se, tangencialmente, o caráter cultural do som, mas sua potência de expressão narrativa da cultura é apenas parcialmente percebida na sua feição musical.

Por outro lado, para além dos "estudos clássicos" do pensamento antropológico, o desenvolvimento do campo de pesquisa da etnomusicologia e as pesquisas decorrentes deste vêm contribuindo com a discussão sobre o som nas ciências sociais, investigando a cultura a partir das sonoridades musicais produzidas por grupos e populações. Este disciplina se constitui, como aponta Tiago de Oliveira (2001) em seu artigo "Som e música: questões de uma antropologia sonora", na interface entre a musicologia e a antropologia, atribuindo-se seus conteúdos à primeira e a metodologia à segunda. Para a etnomusicologia, o som é considerado a partir de dois aspectos: 1) é um fenômeno físico que se insere em contextos culturais (ou seja, relacionado à acústica), e por outro lado, 2) quando "culturalmente organizado" o som é música. Neste caso, pode-se entender que o som em si é um fenômeno físico e só funciona como fenômeno da cultura se for concebido musicalmente ${ }^{5}$. Ao mesmo tempo, a música é tida como um fenômeno de interação social na medida em que é realizada

\footnotetext{
${ }^{4}$ Referimo-nos a obras como: Lévi-Strauss, Claude. Olhar, escutar, ler. São Paulo, Companhia das Letras, 1997; Tristes Trópicos, Companhia das Letras, 1996. Antropologia Estrutural, ed. Tempo Brasileiro, 1996. Mito e Significado, edições 70, 2000, entre outros.
} 
por uma pessoa, para outras pessoas, ou seja, a música precisa ser entendida e estudada tendo em vista o contexto a partir do qual é produzida. Sob esta perspectiva, a música, ou a produção sonora de um determinado grupo, está intimamente relacionada com a performance, ou seja, com fenômenos de interação, representação, ritualização de dramas sociais (Oliveira; 2001) onde a música é vista como prática social, como processo e não produto de ações coletivas, de dinâmicas sociais, etc.

Esta síntese bastante primária, situa a filiação da etnografia sonora no interior de todo um percurso de investigação orientado pelos estudos em etnomusicologia. Em seu artigo Tiago de Oliveira (2001) desvenda o percurso dos estudos em etnomusicologia, seus desdobramentos e aproximações com a Antropologia. Foi neste artigo que encontramos inspiração para proceder a algumas diferenças entre o que estamos pesquisando no BIEV e outras pesquisas antropológicas desenvolvidas a partir da forma sonora que adota um fenômeno cultural, tanto quanto atribuímos à leitura deste artigo nossa intenção de estabelecer certos vínculos entre o campo de estudos já clássico da etnomusicologia, em Antropologia, e as fronteiras possíveis de uma etnografia sonora para o estudo da memória coletiva, estética urbana e duração no mundo contemporâneo, no interior do qual nos propomos então pensar os desdobramentos das idéias deste artigo.

Um dos primeiros pontos controversos abordado pelo autor diz respeito justamente da diferenciação que se estabelece usualmente entre som e som culturalmente organizado (música). Ou seja, da separação entre o som como fenômeno físico, colocado então como objeto de estudo da acústica, e o som "na forma de" música, e desde esta forma estável culturalmente para nós, considerada objeto de estudo da etnomusicologia e da antropologia. A pergunta que daí deriva é se existiria, de alguma forma, um som não organizado culturalmente? A música ou a produção musical (como a construção de instrumentos, a performance, etc) certamente se configuram como uma manifestação cultural através de sons, mas seria possível se pensar o campo da acústica e do som tomado como fenômeno da física ondulatória como algo que não seja culturalmente/humanamente organizado? Estaria o som construído pelo pensamento científico fora dos significados culturais e a acústica se situaria para além das formas de organização social do pensamento humano sobre o mundo das coisas e dos objetos?

Esta diferença cria aqui uma clivagem problemática para o que estamos denominando aqui de etnografia sonora, pois coloca o fenômeno sonoro em um outro estatuto dentro da

\footnotetext{
${ }^{5}$ Para maiores considerações ver Oliveira, Tiago. "Som e Música. Questões de uma antropologia sonora", Revista de Antropologia, vol. 44, no. 1, 221-287, 2001, Departamento de Antropologia, USP.
} 
cultura, ou seja, não apenas como uma produção, ou mesmo um processo tido como artístico, performático, etc, mas como destituído de sentido "cultural" por sua matéria estar referida a sua forma mais "bruta" tendo em vista, digamos assim, sua "manifestação desorganizada" como parte das formas sensíveis da vida social.

Georg Simmel (1996), ao abordar o conceito de paisagem, comenta que uma tal noção não se origina como um fenômeno da ordem da Natureza uma vez que o que seria da ordem do natural é da ordem da indistinção. Para este autor, a paisagem se anuncia precisamente quando coisas e os objetos do mundo não mais se encontram justapostas sobre um pedaço de solo, isto é, quando o mundo natural deixa de ser ingenuamente olhado. Para o caso do som e das sonoridades, na música ou na física ondulatória, pode-se afirmar o mesmo, ou seja, eles só existem enquanto singularidades para o espírito humano na medida em que são arrancados da unidade indivisível da natureza. Enxergar o som como extrato da natureza de um fenômeno físico, é também lhe reservar um enquadre cultural. As leis da acústica retiram a base material do som de uma indeterminação procurando sua unidade na referência um extrato da natureza e que o distancia completamente da homogeneidade do mundo natural.

Da mesma forma que é o olhar humano inteligente que cria a paisagem, reunindo o mundo das coisas e dos objetos, agrupando-os seja de um modo ou de outro, deslocando-os de seus lugares de origem, atuando nas especificidades de cada um de várias maneiras, fazendo variar o seu centro e os seus limites, o ouvido humano modula ritmicamente tudo o que ouve para melhor escutar. O conceito de stimmung da paisagem em Simmel, isto é, a unidade que o mundo das coisas apresenta, manifesta-se através da consciência imaginante do espectador, de "um estado psíquico", orientado segundo um ato reflexo afetivo daquele que especta as coisas exteriores através do ato de nela depositar seus estados de consciência. Isto pode ser aqui uma inspiração para os desdobramentos de se pensar as fronteiras conceituais de uma etnografia sonora no âmbito da Antropologia Urbana. Pensar uma etnografia sonora nas modernas sociedades complexas, urbano-industriais conteria este desafio de se pensar a cidade e suas sonoridades na modalidade dos estudos de paisagens sonoras. Paisagens sonoras são interpretadas a partir de uma unidade perceptível que reúne, ao mesmo tempo, os sons e as formas da vida coletiva desde os pontos de escuta do antropólogo no interior do próprio acontecimento a ser etnografado.

Neste sentido, os sons produzidos pela natureza, dos fenômenos naturais, tanto quanto o fabricado pelas sociedades e as culturas, participariam das formas de ouvir e escutar do próprio antropólogo em sua partilha do sensível que conforma a própria forma da vida coletiva na qual ele participa. Os sons como objetos de uma pesquisa sobre o tempo, a 
memória e a duração não seriam objetos inertes ou inanimados, mas, pela ação do espírito humano sobre o mundo das coisas e dos objetos, comporiam paisagens pelo apelo estético as formas da vida coletiva que eles aludem. Nos termos de Simmel (1996:23): tendo assim como atributo toda a sua objetividade como paisagem no próprio nascedouro da nossa atividade criadora, a Stimmung, expressão ou dinâmica particulares desta atividade, encontra plena objetividade nela (na paisagem).

Desde aí é que podemos pensar uma antropologia sonora onde as sonoridades da vida cotidiana ganham o estatuto de paisagem repleta de sentidos, fruto de um deslocamento não apenas da visualidade para a audição, mas tratando-se de uma escuta dos sons do cotidiano e não apenas das sonoridades na forma de música. Retomando o que foi colocado no inicio deste texto a respeito do lugar dado ao ouvir, por Roberto Cardoso de Oliveira (2000), no trabalho do antropólogo, esta paisagem composta de sons ganha sentido no encontro etnográfico estabelecido entre pesquisador e as formas de expressão cultural de um grupo ou comunidade dadas nas suas práticas cotidianas. Para o caso das pesquisas em etnografia sonora que tem sido realizadas no contexto do Banco de Imagens e Efeitos Visuais, posicionar-se epistemologicamente para uma escuta atenta dos fenômenos sociais diz respeito a esta predisposição ao estranhamento do ordinário, do cotidiano, as surpresas e descobertas da voz do outro em todas as suas dimensões estéticas - entonações, sotaques, expressão de sentimentos - na combinação com os sentidos expressos em seus conteúdos de fala. Trata-se precisamente de uma condição de interpretação da vida coletiva, da memória e da duração das formas da vida social a partir das imagens sonoras com que se expressam.

Ainda na perspectiva de uma microantropologia, voltar-se para as sonoridades da vida cotidiana é partir do pressuposto de que as práticas cotidianas (De Certeau, 1994) dos habitantes da cidade, seus gestos e formas de estar no mundo guardam um sentido "oculto" que se presta a interpretação para além da visualidade. Colocar-se a disposição dos sons e a partir daí refletir sobre a cultura, sobre as artes de dizer e fazer dos grupos com os quais compartilhamos momentos de conhecimento de si e do outro, comporta uma dimensão de partilha do sensível (Rancière; 2005) não evidente no que tange o trabalho etnográfico.

Etnografia sonora e o realismo poético na pesquisa antropológica sobre a cidade moderna

O estudo do som como forma sensível através da qual os antropólogos atingem a compreensão de determinados arranjos da vida social, no interior de uma dada cultura, não é, 
como vimos, algo original para a construção do pensamento antropológico, nem mesmo para a prática da investigação que ele orienta.

Entretanto, raro tem sido os estudos antropológicos que têm se preocupado em refletir sobre o fenômeno sonoro banal e ordinário da vida cotidiana na sua dimensão etnográfica autônoma e irredutível de interpretação das formas sensíveis de uma cultura falar de si e se deixar ouvir pela escuta antropológica. O fenômeno sonoro se destaca pelas discursividades que cria, emancipando as sonoridades de seus contextos originais, resumindo atos de fala, centrada na inteligibilidade que cria, nem tanto pela poética que encerra.

Nos procedimentos sob os quais repousa a etnografia sonora, advogamos uma outra forma de relação do antropólogo com a cidade por ele pesquisada mais próxima do simbolismo das formas que os corpos, os gestos, os objetos e as falas ordinárias adquirem e retém do que no conteúdo sociológico que nele se depositam. Mais pela forma como a vida coletiva num grande centro urbano afeta o próprio antropólogo pela via de seu realismo poético (Sansot, 1986).

O fenômeno sonoro e das sonoridades configuram-se como símbolos que revelam a floração do sensível na imaginação: o gesto, o sentimento, etc. A etnografia sonora trata de uma re-coleção de sentidos que presidem as formas de vida humana num dado tempo e espaço, resultado do engajamento do antropólogo no dado sensível que através delas se manifestam. A pesquisa antropológica através do som trata, assim, do estudo das formas sonoras que pressupõem a existência deste fenômeno como dado da cultura humana. Não se trata da consciência do sentido que o som carrega como fenômeno social, mas de interpretar suas expressões culturais. O simbolismo de que sons são portadores no plano da memória coletiva faz com que eles, portanto, não sejam nem meras emanações e vestígios sensíveis das formas de vida que adotam as sociedades humanas e nem se reduzam à prática social que os fundam, sendo apenas um epifenômeno desta (Durand,1984).

Desde a perspectiva da pesquisa antropológica da e na cidade tomando-se esta como objeto temporal, isto é, como parte de uma reflexão antropológica sobre cotidiano, memória coletiva, estética urbana e duração, o método etnográfico necessita se desprender do reconhecimento de um princípio de causalidade material no interior da dinâmica dos arranjos das formas da vida social no contexto das grandes metrópoles contemporâneas, para penetrar nos processos que presidem a propagação de tais formas no interior de seu corpo coletivo. A etnografia sonora se apresenta, neste caso, como mais um destes procedimentos (etnografia da duração, etnografia de rua) através dos quais pretendemos, no interior da pesquisa do BIEV, atingir uma compreensão das motivações simbólicas e os processos sensíveis profundos que 
propiciam a um corpo coletivo se propagar a partir do encadeamento de certas formas da vida social nas grandes cidades urbano-industriais.

Movimento, transformação, continuidade, descontinuidade, a cidade é metáfora do tempo como fenômeno plural. Na cidade moderno-contemporânea através da alteração de suas formas é que instituem as transformações de seus lugares. A descontinuidade de suas formas nos dá a impressão de uma mudança, entretanto, não aleatória, mas constante e contínua, pois que microscopicamente uma tal transformação, no tempo vivido de seus habitantes, é experienciada como ilusão de uma duração. A descontinuidade temporal da cidade é tecida, assim, no encadeamento sobreposto de suas formas que permitem com que a vida cotidiana dos indivíduos e/ou grupos transcorra fora de uma pulverização de instantes temporais, sob pena de aí ocorrerem fraturas sociais.

A coerência da vida urbana, portanto, sua causalidade material, no interior desta rítmica da mudança tem por base uma irregularidade na propagação de suas formas que necessita ser arranjada para que o seu corpo coletivo possa perdurar. Portanto, não é o movimento que caracterizaria as grandes cidades moderno-contemporâneas, mas o ritmo e duração de suas mudanças responsáveis por atribuir qualidades espaciais as suas formas de vida coletiva. Nos termos bachelardianos, a cidade moderno-contemporânea integra a inquietude de seu corpo coletivo e restitui sua recusa de um tempo morto, abstrato, impessoal para os seus territórios de vida.

Para se pensar a etnografia sonora tal qual estamos propondo aqui para o estudo da memória coletiva, estética urbana e a duração necessitamos evocar os comentários de G. Bachelard (1989) a respeito das três potências do cogito que necessitamos percorrer para atingir a compreensão da cidade como objeto temporal, mais do que expressão de suas durações físicas. Não sem antes deixarmos claro e evidente que este estudo se situa no interior de uma reflexão interpretativa das formas sensíveis que a vida social adota nas modernas sociedades complexas, em especial no espaço da vida metropolitana. Portanto, é sobre o cogito sonhador que estamos nos referindo aqui: pensar antropologicamente a cidade é pensála se pensando a partir daqueles que a pensam, incluindo-se aí o próprio antropólogo na figura do narrador (Eckert, Rocha: 2005).

Sob este enfoque, a matéria urbana do sonoro é, assim, etnografada desde o seu apelo ao sentido das formas que a vida coletiva assume nas grandes metrópoles; desde o eixo de um pensamento poético como parte do dinamismo interno do pensar do antropólogo na cidade no interior da partilha sensível de seus espaços com seus habitantes. Uma etnografia que sonha o interior da matéria dos fenômenos sonoros presente à vida urbana, antes de se tornar 
espetáculo da consciência (Bachelard, 1989). Para Bachelard, a primeira potência do cogito (1) se inscreve na representação referida a uma causalidade eficiente entre a coisa e o pensamento; a segunda potência do cogito (2) está comprometida com a causalidade final, ou seja, do pensamento que pensa a coisa e desde aí, toma consciência de si como condição de pensá-la; e, finalmente, a última potência do cogito (3) a do pensamento que não está aprisionado na matéria da coisa ou na consciência de si, mas desprende-se dela tanto quanto da forma de pensá-la, comprometido com o ato de pensar como atividade estética pura, ou seja, configuradora de formas.

Para se atingir a potência de formalização que constitui a pesquisa antropológica com o fenômeno sonoro no plano dos estudos da memória coletiva, estética urbana e duração, necessita-se atingir esta terceira potência do cogito, superando, portanto, os estágios primeiro e segundo das formas de se pensar os fenômenos sonoros, a expressão física de sua matéria lacunar tanto quanto as formas bem ordenadas a elas atribuídas, e adentrar os seus valores rítmicos e ondulatórios pela via da dialética temporal que lhe atribui a sua matéria uma duração. Na pesquisa que se desenvolve no BIEV, a matéria sonora contempla as marcas da matéria do tempo, pois ela só existe num tempo que vibra. Sensível ao ritmo das ondulações de sua matéria, os sons não se limitam ao espaço desde onde se originam, ao se propagarem, os sons não são indiferentes à matéria do tempo. Ao contrário, os sons são afetados por ela, só subsistindo no interior da duração de suas ondulações.

A matéria do tempo é perecível, lacunar e acidentada e para que tal matéria possa durar ela necessita da função fantástica que preside a memória, espaço onde ela pode repousar e ter uma vibração feliz. Isto é evidente quando se pensa, por exemplo, as formas de se depositarem das lembranças de um corpo coletivo no interior de uma comunidade qualquer. Tais lembranças para perdurarem, e isto a ponto de se conformarem como uma forma a vida social, necessitam vibrar e ondular ritmicamente no interior do seu corpo coletivo, a ponto de se estabilizarem como fenômeno que lhe é próprio. Da mesma forma ocorre com a matéria sonora, pois para que um som perdure sua matéria necessita vibrar na regularidade de uma freqüência. O som só adquire sentido pela forma como se faz ondular sua matéria.

Há, portanto, uma relação estreita entre a etnografia sonora e os estudos de uma etnografia da duração nas modernas sociedades complexas. A forma sonora não é matéria inerte e grosseira, ao contrário, ela é pura vibração uma vez que é a reversibilidade da matéria da ondulação em ondulação da matéria que configura a sua substância. Sob este aspecto, tanto para a etnografia da duração quanto para a etnografia sonora é a disciplina da atividade rítmica entre forma e a 
matéria da vida coletiva aquela que é solicitada ao antropólogo interpretar e compreender em seu trabalho de campo.

Por tudo o que abordamos acima, a pesquisa com a etnografia sonora se depara assim, com a negação de uma interpretação hipostasiada da própria forma da vida social como matéria inerte. Para se interpretar o fenômeno sonoro é necessário, portanto, a adesão do antropólogo a uma interpretação ondulatória da vida social, à densidade dos sentimentos que nascem de suas fontes emissoras, no esforço de consolidar suas propriedades profundamente descontínuas. Deste modo, reconhece-se que toda a forma social como dado sensível tem seus timbres, suas tonalidades, seus ecos e ressonâncias, sons que se harmonizam em ritmos superpostos, ricamente orquestrados, em particular quando oscilam no interior da composição ordinária da vida cotidiana das grandes cidades metropolitanas.

Nesta perspectiva, a etnografia sonora se torna extremamente complexa precisamente porque o antropólogo urbano necessita seguir o caráter material ondulatório e rítmico do próprio fenômeno além de sua irradiação no interior das grandes metrópoles, elas próprias formadas de uma matéria em constante ondulação. Som e cidade compartilham entre si, no plano da imaginação criadora, um simbolismo dinâmico. $\mathrm{O}$ fenômeno da vida urbana como o fenômeno sonoro em sua dimensão sensível, não são indiferentes ao tempo, compostos de matérias que não são indiferentes nem às rítmicas nem às ondulações do tempo. A realização de etnografias sonoras na cidade atribui, assim, importância considerável de outras práticas etnográficas no interior da Antropologia Urbana e que geralmente foram por muito tempo excluídas de seu campo de preocupações, ou seja, ao papel das emoções, dos afetos, das sensações, do imaginal como partícipe da construção da representação etnográfica das modernas cidades urbano-industriais (Maffesoli,1990).

A proposta de uma antropologia sonora está centrada, assim, nos sons e suas sonoridades como dados sensíveis que comportam a experiência humana no mundo. Os sons são, neste sentido, dispositivos simbólicos profundamente abertos e dinâmicos, em permanente construção, com profunda filiação às formas da vida coletiva e aos seus contextos cósmicos e sociais de origem. Em sua feição arqueológica, uma etnografia dos sons urbanos, no plano do estudo da memória coletiva e da duração, apela à matéria das transformações de tais formas, abertas à instabilidade das práticas sociais diversificadas no contexto das grandes metrópoles contemporâneas. $\mathrm{O}$ estudo das formas sonoras que assume a vida coletiva nas modernas sociedades complexas como expressão movente dos arranjos de seu corpo social reúne as formas sensíveis que ele assume a sua inteligibilidade. 


\section{Bibliografia}

BACHELARD, G. La dialectique de la durée. Paris, PUF,1989.

BACHELARD, G. La poétique de la rêverie. Paris, PUF, 1993.

BOAS, F. A Formação da Antropologia Americana, 1883-1911. Organizador: Stocking,

George W. Contraponto Editora, 2004.

CARDODO DE OLIVEIRA, R. O trabalho do antropólogo : ver, ouvir e escrever. Brasília:

Paralelo 15, São Paulo Editora UNESP, 2000.

CERTEAU, M. de. A Invenção do Cotidiano. Artes de fazer. Rio de Janeiro, Vozes, 1994.

CERTEAU, M. de. A Escrita da História. Rio de Janeiro, Forense Universtária, 2002.

CHION, M. Le son.Paris, Armand Colin, 2004.

DURAND, G. Les structures anthropologiques de l'imaginaire. Paris, Dunod, 1984.

ECKERT, C. \& ROCHA, A.L. da. "Imagens do tempo nos meandros da memória: por uma etnografia da duração". In ECKERT, Cornelia; ROCHA, Ana Luiza Carvalho. O Tempo e a Cidade. Porto Alegre, UFRGS, 2005.

KRISTEVA, J. A História da Linguagem, edições 70, 1999.

LEVI-STRAUSS, Claude. Tristes Trópicos, Editora: Companhia das Letras, 1996.

LEVI-STRAUSS, Claude. Antropologia Estrutural, ed. Tempo Brasileiro, 1996.

LÉVI-STRAUSS, Claude. Olhar, escutar, ler. São Paulo, Companhia das Letras, 1997

LEVI-STRAUSS, Claude. Mito e Significado. Edições 70, 2000.

LEVI-STRAUSS, Claude. Mitológicas I, O Cru e o Cozido. Cosac-Naify, 2004.

MAFFESOLI, M. Aux creux des apparences. Paris, Plon, 1990.

MAFFESOLI, M. La connaissance ordinnaires. Paris, Klincksieck Méridiens, 1994.

MEAD, Margaret. "Visual Anthropology in a discipline of words", In : Principles of Visual Anthropology, Paul Hockings (ed.), Mouton Publisher (1975).

RANCIERE, Jacques. A Partilha do Sensível, estética e política.Ed. 34, 2005

ROCHA, A.L. da "Antropologia das formas sensíveis: entre o visível e o invisível, a floração dos símbolos". Revista Horizontes Antropológicos, Porto Alegre, ano 1, 1995.

SANSOT, P. La poétique de la ville. Paris, Klincksieck Méridiens, 1988.

SANSOT, P. Les formes sensíbels de la vie sociale. Paris, PUF, 1986.

SANSOT, P. Le goût de la conversation. Paris, Desclée de Brouwer, 2003.

OLIVEIRA, T. de "Som e Música. Questões de uma antropologia sonora". Revista de Antropologia vol.44 no.1. São Paulo,2001.

SIMMEL, G. A filosofia da paisagem. REVISTA POLÍTICA \& TRABALHO, João Pessoa, $\mathrm{n}$ ${ }^{\circ} 12,1996$.

SIMMEL, G. Philosophie de la Modernité. La femme, la ville, l'individualisme. Paris, Payot \& Rivages, 2004. 